\title{
Traumatic anterior cervical pseudomeningocele causing intracranial hypotension successfully treated with blood patch: case report
}

\author{
Edwin A. Takahashi, MD, ${ }^{1}$ Laurence J. Eckel, MD, ${ }^{1}$ Felix E. Diehn, MD, ${ }^{1}$ Kara M. Schwartz, MD, ${ }^{1}$ \\ Christopher H. Hunt, MD, ${ }^{1}$ and David J. Daniels, MD, PhD²
}

Departments of ${ }^{1}$ Radiology and ${ }^{2}$ Neurosurgery, Mayo Clinic, Rochester, Minnesota

\begin{abstract}
Cervical pseudomeningocele is a rare complication of trauma. It develops when an extradural collection of cerebrospinal fluid (CSF) develops after a dural breach. The authors present the unusual case of a 33-year-old man with progressive headache, neck pain, mental status changes, and cardiopulmonary instability after polytrauma sustained from a motorcycle-versus-deer collision, without improvement during a 5-day hospitalization. Magnetic resonance imaging revealed a collection of CSF anterior to the cervical thecal sac compatible with an anterior cervical pseudomeningocele. A nontargeted epidural blood patch was performed with subsequent resolution of the patient's symptoms. Anterior cervical pseudomeningoceles are usually asymptomatic; however, these lesions can cause orthostatic headaches, neck pain, and cardiopulmonary compromise, as it did in the featured patient. Pseudomeningoceles should be included in the differential diagnosis for posttrauma patients with progressive neurological decline or postural headache, and blood patch may be an effective minimally invasive treatment.
\end{abstract}

http://thejns.org/doi/abs/10.3171/2014.12.SPINE14735

KEY WORDS blood patch; cervical; MRI; pseudomeningocele; trauma; technique

$\mathrm{P}$ SEUDOMENINGOCELES are extradural collections of cerebrospinal fluid (CSF) that result from a dural breach. ${ }^{1,2}$ These lesions are typically iatrogenic, a complication from spinal surgery. ${ }^{2,4}$ They can also be congenital, usually occurring in the thoracic or thoracolumbar area, and are associated with diseases such as Marfan syndrome or neurofibromatosis. ${ }^{5}$ In addition, idiopathic pseudomeningoceles have been described, usually in association with a spontaneous CSF leak around a spinal meningeal diverticulum..$^{6-9}$ Treatment in these cases often involves bed rest, blood patch, subarachnoid drainage, or surgical repair. In more rare cases, pseudomeningoceles can be caused by trauma. ${ }^{2,5,6,11,12}$ We present the case of a relatively uncommon posttraumatic anterior cervical pseudomeningocele, with symptoms of intracranial hypotension, successfully treated with a blood patch.

\section{Case Report}

History and Examination

This 33-year-old man sustained polytrauma following a motorcycle collision with a deer. He was not wearing a helmet. He was stabilized at an outside center and transferred to our emergency department. Cervical spine CT revealed an isolated C-6 spinous process fracture (Fig. 1A). Other injuries included a right distal fibular ankle fracture dislocation and bilateral pulmonary contusions. There was no evidence of intracranial pathology. The spinous process fracture was treated with immobilization in a rigid Miami $\mathrm{J}$ cervical collar.

Approximately 24 hours postinjury, the patient complained of extreme neck pain and headache when nursing staff attempted to have him sit up. His pain was mostly postural and improved with flat bed rest. He also exhibited progressively worsening episodes of bradycardia, oxygen desaturation, and mental status changes on elevating his head. In an evaluation for a cardiac or embolic cause, an electrocardiogram, an echocardiogram, and a pulmonary CT angiogram were negative. After 5 days of hospitalization without clinical improvement and given the posterior head and neck pain that was out of proportion to his known injuries, MRI of the cervical spine was performed for persistent symptoms. Imaging studies revealed an extradural fluid collection ventral to the thecal sac and extending

SUBMITTED July 23, 2014. ACCEPTED December 30, 2014.

INCLUDE WHEN CITING Published online May 29, 2015; DOI: 10.3171/2014.12.SPINE14735.

DISCLOSURE The authors report no conflict of interest concerning the materials or methods used in this study or the findings specified in this paper. 

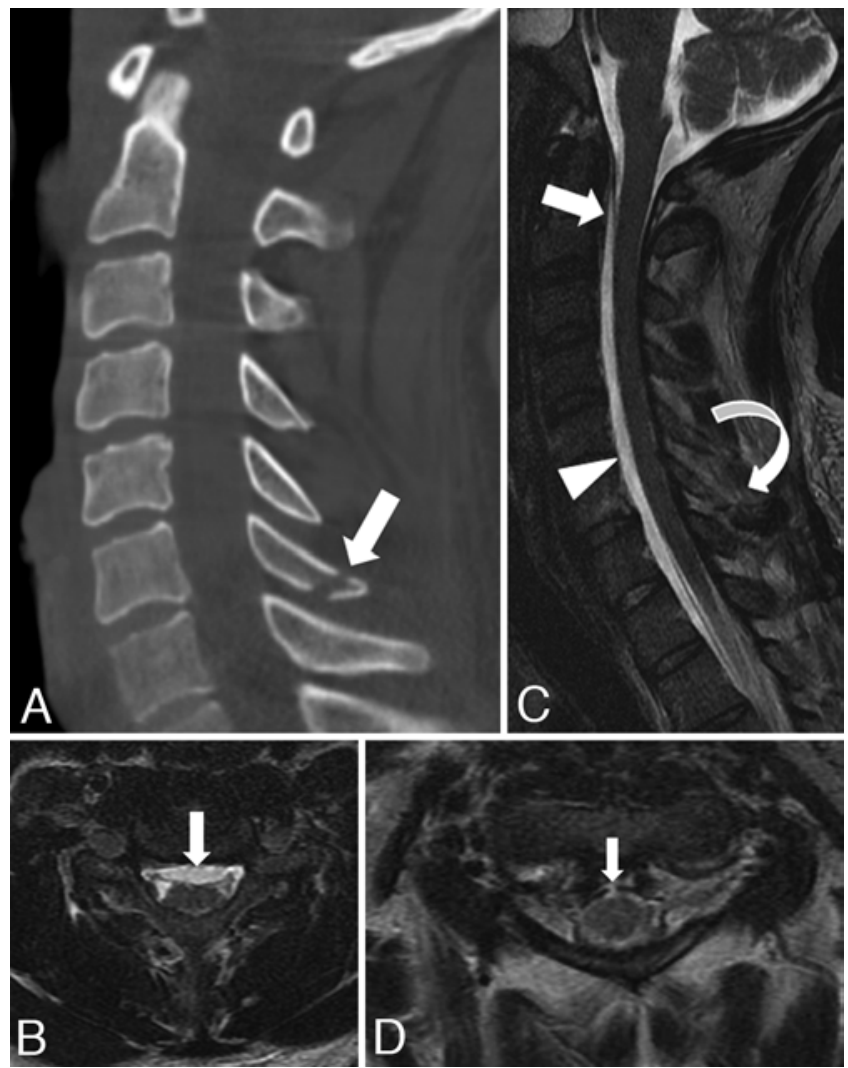

FIG. 1. A: Reformatted sagittal cervical spine CT demonstrates a normal cervical spine, except for a slightly displaced fracture through the spinous process of C-6 (arrow). B: Axial T2-weighted sequence from cervical spine MRI demonstrates a hyperintense ventral extradural fluid collection similar to CSF, slightly flattening the ventral cord (arrow). C: Sagittal T2 image (magnified field of view) shows the ventral extradural fluid collection (arrowhead), the fracture of the C-6 spinous process (curved arrow), and the displaced ventral dural reflection along the superior and inferior cervical spine (arrow). D: Axial T2-weighted sequence (magnified field of view) shows a focal dural disruption ventrally at the level of $\mathrm{C}-2$ (arrow). Findings are compatible with an anterior cervical pseudomeningocele.

from C-2 to the T2-3 interspace, which demonstrated a signal similar to that for CSF (Fig. 1B and C). In addition, a small defect was identified in the ventral dura at the level of C-2 (Fig. 1D). Findings were compatible with a traumatic anterior cervical pseudomeningocele.

\section{Treatment}

The following day, the patient underwent a nontargeted, large-volume epidural blood patch at L1-2 in an attempt to treat his postural symptoms.

\section{Posttreatment Course}

He experienced almost immediate relief of his postural headache and neck pain. His heart rate and oxygen saturation also normalized. At the 2-week, 3-month, and 1-year follow-up visits, he remained asymptomatic.

\section{Discussion}

Traumatic anterior cervical pseudomeningoceles are extremely rare. To the best of our knowledge, only 3 other cases have been reported. ${ }^{6}$ While the targeted epidural blood patch procedure has been described for the treatment of spontaneous and postsurgical pseudomeningoceles that cause intracranial hypotensive symptoms, this is the first report of a successful nontargeted blood patch in the traumatic setting.

The way in which the injection of autologous blood stops CSF leakage is not fully understood. Some propose that the blood patch increases extradural tissue pressure relative to subarachnoid pressure through mass effect, which decreases the gradient for CSF efflux..$^{1,3,10}$ This may explain why patients experience immediate symptomatic relief after the patch injection and may also provide a reason for the efficacy of the nontargeted approach; the mass effect of the blood patch would pressurize the entirety of the dural tube. Clot formation over the dural defect is another possible explanation for the efficacy of the blood patch and may account for the latent effect of the procedure. In this theory, a dural plug, created by the viscous clot, blocks the CSF leak and restores CSF pressure. ${ }^{1,3,10}$ The variability of symptom relief among patients suggests that the mechanism by which the epidural blood patch works is probably multifactorial, and in our case the large volume of blood injected into the patient certainly could have had both effects. Given the limited experience with traumatic pseudomeningoceles, the success rate and long-term symptomatic benefit of this procedure remain uncertain.

Trauma is the least common cause of pseudomeningoceles. ${ }^{4,7,11}$ When these lesions develop after trauma, they often involve nerve roots of the brachial and lumbosacral plexuses. These nerves are anchored between 2 mobile parts, and any forceful distraction can result in nerve root avulsion and pseudomeningocele formation. In these cases, the pseudomeningocele usually organizes in the posterior spinal region. ${ }^{4}$

In our patient, the pseudomeningocele was not identified at the time of presentation, since it was not apparent on the trauma cervical spine CT. Pseudomeningoceles are most often asymptomatic. ${ }^{5,8}$ Patients may present with a variety of symptoms due to compressive mechanisms, including headache, nausea, vomiting, and significant neurological compromise. ${ }^{5,7}$

The preferred modality for investigating pseudomeningoceles is MRI, which reveals a region of low signal intensity on T1-weighted images and high signal intensity on T2-weighted images, similar to CSF.,8 Computed tomography myelography and fluoroscopic myelography may also demonstrate pseudomeningoceles. Myelography combined with CT may be superior to MRI for identifying CSF outflow tracts, and delayed CT myelography may detect a slow-filling pseudomeningocele. ${ }^{5}$ Fluoroscopic myelographic studies can show filling of the pseudomeningocele as well as demonstrate flattening of the thecal sac margin, absence of the nerve sheath, and pulsatile leakage of contrast into the extraarachnoid sacs. ${ }^{5}$

\section{Conclusions}

In summary, anterior cervical pseudomeningocele is a rare complication of spinal trauma. Although usu- 
ally asymptomatic, these lesions can cause orthostatic headache and neck pain, mental status changes, and cardiopulmonary compromise, as occurred in our patient. Therefore, pseudomeningocele should be included in the differential diagnosis for posttraumatic patients with these symptoms. Magnetic resonance imaging is the preferred modality to evaluate for these lesions. Our case demonstrates that a nontargeted epidural blood patch can be an effective option for treating patients with symptoms due to anterior cervical pseudomeningoceles.

\section{References}

1. Clendenen SR, Pirris S, Robards CB, Leone B, Nottmeier EW: Symptomatic postlaminectomy cerebrospinal fluid leak treated with 4-dimensional ultrasound-guided epidural blood patch. J Neurosurg Anesthesiol 24:222-225, 2012

2. Couture D, Branch CL Jr: Spinal pseudomeningoceles and cerebrospinal fluid fistulas. Neurosurg Focus 15(6):E6, 2003

3. Duffy PJ, Crosby ET: The epidural blood patch. Resolving the controversies. Can J Anaesth 46:878-886, 1999

4. Gutiérrez-González R, Boto GR, Pérez-Zamarrón A, RiveroGarvía M: Retropharyngeal pseudomeningocele formation as a traumatic atlanto-occipital dislocation complication: case report and review. Eur Spine J 17 (Suppl 2):S253-S256, 2008

5. Hawk MW, Kim KD: Review of spinal pseudomeningoceles and cerebrospinal fluid fistulas. Neurosurg Focus 9(1):e5, 2000

6. Horn EM, Bristol RE, Feiz-Erfan I, Beres EJ, Bambakidis NC, Theodore N: Spinal cord compression from traumatic anterior cervical pseudomeningoceles. Report of three cases. J Neurosurg Spine 5:254-258, 2006

7. Mathews MS, Owen CM, Hasso AN, Binder DK: Traumatic retropharyngeal pseudomeningocele with atlanto-occipital dislocation in a neurologically intact patient. Neuroradiol J 20:694-698, 2007

8. Morgan SL, Krishna V, Varma AK: Cervical pseudomenin- gocele as a cause of neurological decline after posterior cervical spine surgery. Neurol India 60:256-257, 2012

9. Schievink WI, Meyer FB, Atkinson JL, Mokri B: Spontaneous spinal cerebrospinal fluid leaks and intracranial hypotension. J Neurosurg 84:598-605, 1996

10. Sencakova D, Mokri B, McClelland RL: The efficacy of epidural blood patch in spontaneous CSF leaks. Neurology 57:1921-1923, 2001

11. Tanaka M, Ikuma H, Nakanishi K, Sugimoto Y, Misawa H, Takigawa T, et al: Spinal cord herniation into pseudomeningocele after traumatic nerve root avulsion: case report and review of the literature. Eur Spine J 17 (Suppl 2):S263S266, 2008

12. Weng YJ, Cheng CC, Li YY, Huang TJ, Hsu RW: Management of giant pseudomeningoceles after spinal surgery. BMC Musculoskelet Disord 11:53, 2010

\section{Author Contributions}

Conception and design: Eckel, Takahashi. Acquisition of data: Eckel, Takahashi. Analysis and interpretation of data: Eckel, Takahashi. Drafting the article: Eckel, Takahashi. Critically revising the article: Eckel, Takahashi, Diehn, Schwartz, Hunt. Reviewed submitted version of manuscript: all authors. Approved the final version of the manuscript on behalf of all authors:

Eckel. Study supervision: Daniels.

\section{Supplemental Information}

\section{Previous Presentation}

Presented at the 2013 Annual Symposium of the American Society of Spine Radiology, Scottsdale, Arizona, February 21-24, 2013.

\section{Correspondence}

Laurence J. Eckel, Department of Radiology, Mayo Clinic, 200 First St. SW, Rochester, MN 55905. email: eckel.laurence@ mayo.edu. 